https://doi.org/10.21670/ref.2121084

Artículos

\title{
Un paisaje cultural pampeano en construcción: ordenamiento territorial de la frontera oeste santafesina (Argentina, 1858-1908)
}

\section{A Pampean cultural landscape under construction: territorial organization of the western frontier of Santa Fe (Argentina, 1858-1908)}

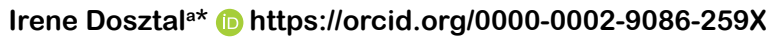

\begin{abstract}
a Universidad Nacional de Rosario, Unidad de Investigación en Historia Regional, Rosario, Argentina, correo electrónico: dosztal@ishir-conicet.gov.ar
\end{abstract}

\section{Resumen}

Este artículo tiene como objetivo abordar la construcción del paisaje cultural pampeano sobre el área fronteriza del centro oeste de la provincia de Santa Fe (Argentina) a lo largo de la segunda mitad del siglo xix y la primera década del xx. La metodología empleada es el análisis del catastro histórico en

Recibido el 13 de julio de 2021.

Aceptado el 22 de noviembre de 2021.

Publicado el 8 de diciembre de 2021.

* Autora para correspondencia: Irene Dosztal. Correo electrónico: dosztal@ishir-conicet.gov.ar

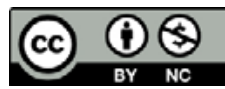

Esta obra está protegida bajo una Licencia Creative Commons Atribución-NoComercial 4.0 Internacional. relación con la bibliografía especializada que, abordados en su dimensión diacrónica, permite la reconstrucción de un paisaje cultural que dejó una impronta definitiva en este sector geográficamente y socialmente fronterizo. A través del mismo se puede observar cómo el área geográfica indicada ve modificada su fisonomía producto del desarrollo colonizador alentado por los diferentes gobiernos en turno. Estos cambios fueron tanto productivos como sociales. Productivo por la parcelación de las tierras y social por la masiva introducción de inmigrantes en su mayoría europeos, considerados aptos para explotarlas y así posicionar a la Argentina en el mercado agroexportador.

Palabras clave: ordenamiento territorial, paisaje cultural, inversión, colonización, frontera.

\section{Abstract}

The aim of this article is to address the construction of the Pampean cultural landscape in the border area of the central western part of the Province of Santa Fe (Argentina) during the second half of the 19th century and the first decade of the 20th century. The methodology used is the analysis of the historical cadastre in relation to the specialized bibliography which, approached in its diachronic dimension, allows the reconstruction of a cultural landscape that left a definitive mark on this geographically and socially frontier sector. It is possible to observe how the geographical area in question underwent

CÓMO CITAR: Dosztal, I. (2021). Un paisaje cultural pampeano en construcción: ordenamiento territorial de la frontera oeste santafesina (Argentina, 1858-1908) [A Pampean cultural landscape under construction: territorial organization of the western frontier of Santa Fe (Argentina, 1858-1908)]. Estudios Fronterizos, 22, e084. https://doi.org/10.21670/ref.2121084 
changes in its physiognomy as a result of the colonizing development encouraged by the different governments of the time. These changes were both productive and social. Productive, due to the division of the land into plots, and social, due to the massive introduction of immigrants, mostly European, who were considered apt to exploit the land and thus position Argentina in the agro-export market.

Keywords: territorial planning, cultural landscape, investment, colonization, frontier.

\section{Introducción}

En términos generales, al inicio del periodo estudiado (1858-1908) lo que hoy se conoce como República Argentina se encontraba en una guerra civil que enfrentaba al Estado de Buenos Aires con el de la Confederación Argentina, compuesta por las provincias del interior. Ambos estados lucharon durante una década por consolidar sus estructuras económicas y político-institucionales y por obtener la unidad y supremacía nacional (Lanteri, 2013). Si bien las diferentes provincias buscaron reforzar la presencia militar en las fronteras, los escasos recursos estaban destinados a solventar sus ejércitos; por lo que la población indígena recuperó buena parte de los territorios de la llamada frontera sur (provincias de Buenos Aires, Santa Fe, Córdoba, San Luis y Mendoza).

Tras la batalla de Pavón (1861) con el triunfo del Estado de Buenos Aires comienza el proceso, que en la historiografía nacional se conoce como pacificación y reorganización nacional llevado adelante por las gestiones de tres presidencias: Bartolomé Mitre (1862-1868), Domingo Faustino Sarmiento (1868-1874) y Nicolás Avellaneda (18741880 ), quienes conformaron una dirigencia de mando heterogéneo, pero con la idea de "nación" como objetivo central (Dosztal, 2017).

En consonancia, asegurar y extender la línea de fronteras de la provincia de Santa Fe fue un asunto de vital importancia para los sucesivos gobiernos de la segunda mitad del siglo xix, ya que contaba con escasos centros urbanos y una población agrícolamilitar dispersa. La venta de tierras públicas y su colonización con inmigrantes europeos fue la principal estrategia para controlar los territorios fronterizos. En esta oportunidad, el enfoque es en cómo repercutieron estas políticas en el departamento San Gerónimo que por su ubicación geográfica estratégica sufrió inmediatamente el impacto de estas nuevas políticas de poblamiento y de modernización (Figura 1).

La mayor parte de las tierras públicas y privadas reconocidas por los sucesivos gobiernos provinciales estaban ocupadas por poblaciones originarias que ponían en riesgo las nuevas políticas al resistir su poblamiento por inmigrantes extranjeros. A esta situación de inestabilidad social se le sumaban varios factores que profundizaban el caos en el régimen organizacional de la provincia: falta de mensuras, registro de propiedad, desconocimiento de la extensión de tierras fiscales, partidismo político, entre otros. 
Figura 1. Plano actual de la provincia de Santa Fe en el cual en verde se delimita el área ocupada originariamente por el departamento San Gerónimo que sufrió modificaciones a lo largo de la segunda mitad del siglo XIX

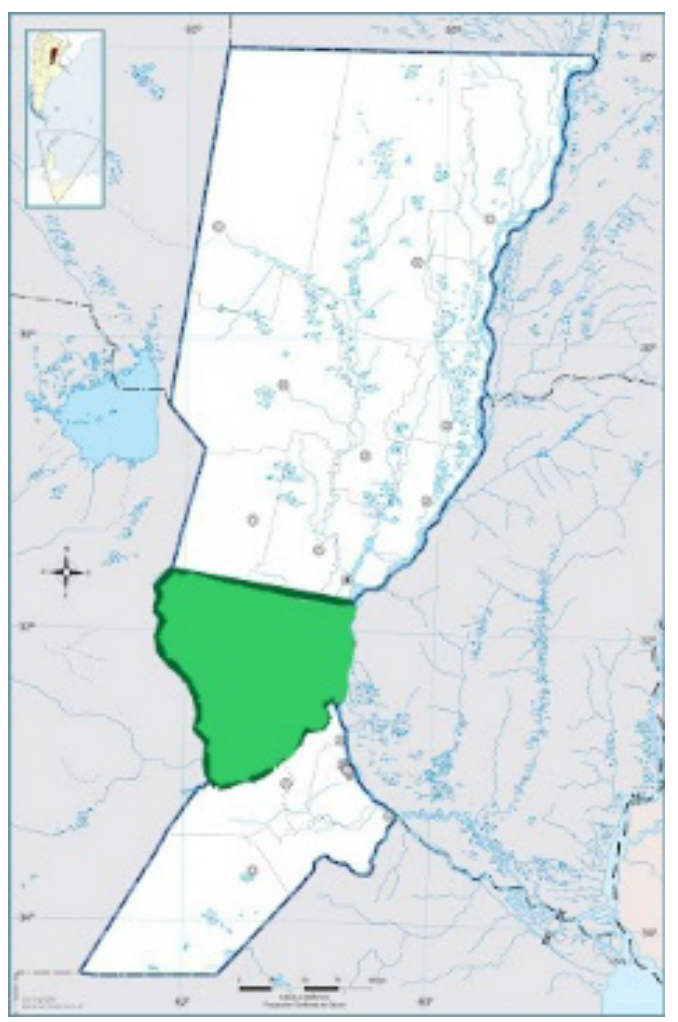

Esta confusa situación en relación con la propiedad y las leyes que regían la tierra pública llevó al gobernador Domingo Crespo (1851-1854) a suspender la venta de tierras fiscales y a llamar a los antiguos dueños de mercedes $^{1}$ a exhibir sus títulos para facilitar el catastro general que se planificaba levantar. Asimismo, se declararon nulas todas las ventas no realizadas a través de subastas públicas y, desde 1855, se les fue devolviendo a los compradores el precio que constara en el registro (Cárcano, 1972).

Estas medidas de control junto a la creación en 1862 del Registro General de Títulos de Propiedad completaban el plan de ordenamiento territorial tendiente a regularizar la tenencia de tierra pública y privada en la provincia.

El primer Registro de la Contribución Directa en el territorio que compete a este artículo, el departamento San Gerónimo, fue levantado en $1858^{2}$ con el objetivo de consignar el nombre y apellido de los propietarios, ubicación, clasificación del capital, avalúo de la finca y monto de contribución directa. Este registro arrojó un total de 128 propietarios, con una marcada producción ganadera como eje de la vida económica,

\footnotetext{
${ }^{1}$ Merced de tierra fue una institución jurídica de la Corona de Castilla aplicada en las colonias de América, que consistió en una adjudicación de predios realizada para incentivar la colonización de las tierras conquistadas (Mejía, 2012).

${ }^{2}$ AgPSF (Archivo General de la Provincia de Santa Fe). Contaduría. Tomo 104. Expte. 18. Registro de la Contribución Directa 1858-1859.
} 
pero en un área reducida del mismo; una franja sobre la costa del Río Paraná hacia 50 $\mathrm{km}$ al oeste de los $14712 \mathrm{~km}^{2}$ que comprendía el departamento (Montenegro, 1994; Frid, 2010).

Esta situación vivió un cambio drástico con la proyección y ejecución de la línea férrea del Central Argentino y la expansión territorial que este proyecto provocó. Esta transformación (que se trata en el primer apartado del artículo) fue a nivel espacial y poblacional: las tierras se revalorizaron y las políticas seguidas por la Compañía de Tierras habilitaron el ingreso de una masa de inmigrantes que se trasladaron a diferentes sectores del departamento; muchos de ellos portadores de un perfil empresarial ingresaron al negocio rural en San Gerónimo.

Con el fin de abordar este proceso de transformación se analiza, en una primera instancia, la evolución de la tenencia de la tierra como consecuencia de una política de poblamiento que provocó el loteo y venta de tierras fiscales y privadas que se inicia con la proyección (1853) y ejecución (1863-1870) del ramal Rosario-Córdoba del Ferrocarril Central Argentino que unía el principal puerto de la provincia de Santa Fe con la provincia de Córdoba, ubicada en el centro del territorio nacional.

Este ramal atraviesa en tierras santafesinas a los departamentos Rosario y San Gerónimo; en este último se hace el enfoque por ser su área oeste no solo el límite jurisdiccional con la provincia de Córdoba sino también una frontera sociogeográfica tanto por las características de sus tierras como por el perfil poblacional. Entonces, la proyección de Ferrocarril Central Argentino significó un plan de expropiación de tierras privadas, la mensura y venta de tierras fiscales.

A continuación, se caracteriza ese espacio fronterizo tanto a nivel geográfico como poblacional para, luego, adentrarse particularmente en la evolución territorial del departamento San Gerónimo. Dicha reconstrucción permitirá plantear a las colonias agrícolas como nuevas unidades territoriales productoras de materias primas a cargo de familias colonas que dan comienzo a la construcción de un paisaje cultural pampeano que persiste hasta la actualidad. Se entiende por paisaje cultural pampeano a la consolidación de un proyecto que tuvo como eje la fundación de colonias agrícolas pobladas y explotadas por inmigrantes en su mayoría europeos. Es decir, las tierras, que parecían infinitas, se delimitaron con alambrado; y las construcciones de ladrillos fueron emergiendo en el ambiente y lo convirtieron en un paisaje ruralizado con pautas de ocupación del espacio, relaciones sociales y formaciones socioeconómicas que representaron un panorama dispar al anteriormente conocido en la región.

Por último, para dar cuenta de esta construcción de un nuevo paisaje cultural se analizan comparativamente mapas catastrales de la provincia de 1867, 1872, 1889, 1895 y 1901 con bibliografía que conforma el corpus de antecedentes para mostrar cómo evolucionó esa tenencia de la tierra a través de su parcelación y venta, específicamente en el departamento, así como las políticas de colonización que fomentaron la inversión privada a sectores fronterizos que en décadas anteriores eran vistos como inhóspitos e improductivos.

\section{El Ferrocarril Central Argentino: motor de la transformación territorial}

La firma del contrato en marzo de 1863 entre la compañía británica y el Estado nacional dio inicio a un proceso de transformación territorial que comenzó a modificar para 
siempre un paisaje con resabios coloniales poco habitado, con flacas reses y vientos fuertes (Ferns, 1968) y lo convirtió en una promesa de modernidad. Esta operación contaba con dos propósitos: el tendido ferroviario y la colonización de sus tierras marginales para garantizar el tráfico constante en la región, pero desde el comienzo de las negociaciones el contrato final fue considerado por las autoridades gubernamentales (nacionales y provinciales) como una concesión excesiva y controversial que dejaba en desventaja a la Nación (Scalabrini Ortiz, 1958; Wilcken, 1873).

Por contrato, el gobierno concedió a la compañía la propiedad total de una legua $(5 \mathrm{~km})$ a cada lado de las vías en toda su extensión, que comenzaba a una distancia de cuatro leguas de las estaciones de Rosario y Córdoba (Miguez, 1985) y para su manejo la compañía ferroviaria creó: The Central Argentine Land Company (Calco). Para la época, esta fue la compañía monopólica que administró el espacio continuo de tierras lindantes a los $396 \mathrm{~km}$ de rieles que unían las ciudades de Rosario y Córdoba. Se trata de 346727 hectáreas que, previo a la plena concesión, debían ser expropiadas a sus dueños quienes hasta la fecha las habían explotado (Dosztal, 2018).

El proceso de expropiación llevó a una negociación engorrosa entre los funcionarios y los propietarios que reclamaban ya fuera por la violación hacia sus derechos como por la especulación financiera. No olvidemos que esas tierras subirían de valor automáticamente una vez que las vías férreas las atravesasen. Por tal razón, el ministro del interior, G. Rawson, aconsejó tasar las tierras para su adquisición sin considerar esta mejora; fue así como entre 1867 y 1881 las tierras fueron enajenadas y el sector de las estancias dejó de pertenecer a sus dueños primitivos para pasar a manos de la Compañía de Tierras.

Para cubrir el precio de compra y gastos judiciales, ambas provincias, Santa $\mathrm{Fe}$ y Córdoba, cedieron al Estado nacional tierras fiscales. Al respecto, la provincia de Santa Fe, bajo la ley del 6 de marzo de 1864, puso a disposición los terrenos fiscales comprendidos:

al Norte, la prolongación del costado Norte del terreno propiedad de D. Cosentino Fontanilla hasta alcanzar la Cañada San Antonio. Al Sur, los terrenos propiedad de D. Miguel Otero, situado sobre el arroyo Tortugas. Al Este: el límite Oeste de las propiedades enajenadas por el Fisco durante la administración de D. Juan Pablo López pertenecientes los a D. Cosentino Fontanilla, D. M. Saavedra, D. Thomas Armstrong, D. S. Lafone y otros. Al Oeste: el arroyo Las Tortugas y Cañada San Antonio límite Oeste de la provincia. (Ministerio de Gobierno, 1866, p. 414)

Este antecedente documental colocó en el negocio inmobiliario una fracción de terrenos hasta la fecha marginales ubicada sobre la frontera centro oeste provincial cuyo límite interprovincial se definió hasta 1886. Se trataba de 175597 leguas cuadradas, ${ }^{3}$ es decir, 474287 ha, divididas en 53 suertes de estancias ${ }^{4}$ cuya superficie abarcaba desde 1083 a 4 leguas cuadradas (2 925 ha a 10804 ha). El agrimensor encargado del trabajo los describió a modo general como "campos con pastos fuertes, buenos y abundantes;

${ }^{3}$ La legua cuadrada española se usó en las regiones de asentamiento anterior a 1879 y equivalían a 2701 ha (Miguez, 1985).

${ }^{4}$ La suerte de estancia era una medida de superficie que debía tener por lo menos una legua y media de largo por media de ancho, con uno de sus cabezales linderos a una aguada para proveer de agua al ganado (Reguera, 1999). 
sus montes no cuentan con maderas aptas para las construcciones rurales y de las 53 suertes solo 25 cuentan con aguadas naturales en las Cañadas que las cruzan" (Ministerio de Gobierno, 1866, p. 453). En 1866 comenzaron sus ventas a través de subasta pública y se inició la ocupación y explotación de un espacio fronterizo que de buenas a primeras se convertía en el hinterland del centro productivo conformado por las colonias del ferrocarril; y, a la vez, se habilita al servicio público la primera sección de la línea que llega hasta la actual Cañada de Gómez y en 1867 la misma llegaba a Villa María (Córdoba).

El plano topográfico realizado por el ingeniero Albano M. de Laberge para el Central Argentino (1867) es el primer antecedente cartográfico (Figura 2) que se ha podido rastrear que plasma la antigua división de tierras, previa al paso del ferrocarril, en la que las estancias contaban como uno de sus límites un curso de agua para su ganado, tanto hacia el río Carcarañá como hacia las diferentes cañadas que surcaban el territorio. También da cuenta de la expansión territorial (1858-1864) que transformó tanto el espacio como los actores del mundo rural de San Gerónimo como resultado de los nuevos esquemas en la valorización de los terrenos en relación con el tendido del ferrocarril; producto de las políticas seguidas por las compañías de tierras, así como también a la apertura de nuevas estrategias implementadas por los empresarios que ingresaron al negocio rural en San Gerónimo.

Figura 2. Plano elaborado por De Laberge en 1867, modificado por la autora para remarcar la delimitación geográfica del departamento San Gerónimo y el área específica de tierras públicas subdivididas en suertes de estancia. Primer antecedente de control territorial de la región

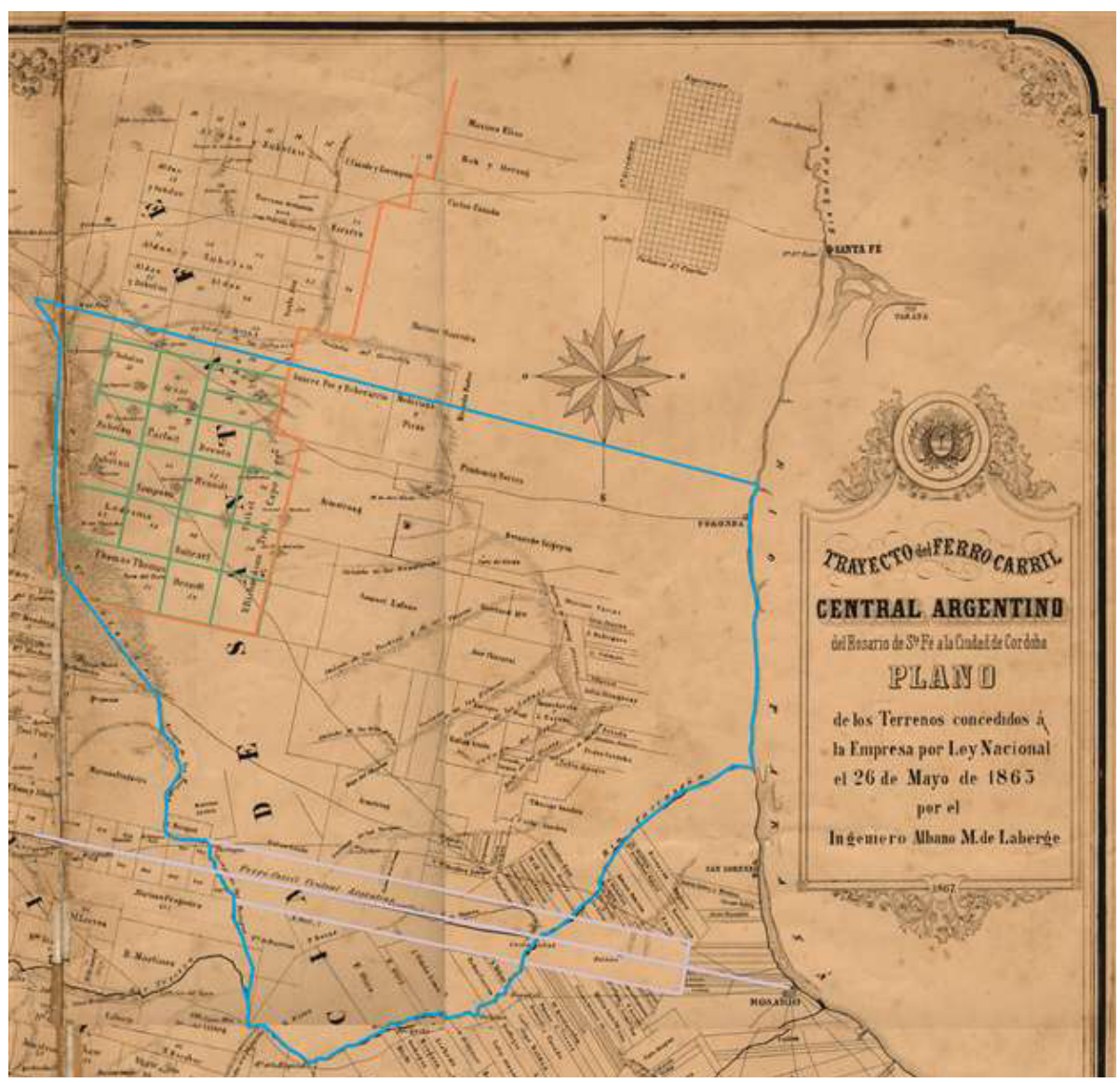


En el plano de la Figura 2 se han delimitado los límites del departamento (en celeste) para mostrar cómo lo iba a atravesar el trayecto más extenso del tendido ferroviario. El Estado nacional tuvo que compensar con el dinero obtenido por la venta de tierras fiscales a los 52 dueños de esas tierras (en gris). Estas estancias dedicadas netamente a la ganadería necesitaban para su funcionamiento acceso libre a cursos de agua por lo que es relevante resaltar el testimonio de los dueños Pedro y Ramón Araya, por ejemplo, quienes en una carta fechada el 18 de agosto de 1864, exponían "que la expropiación de una lonja de una legua privaría a su establecimiento de la parte más importante del terreno y lo dejará completamente inutilizado" (Scalabrini Ortiz 1958, p. 131), es decir, con dicha expropiación se le quitaba el sector de las estancias que lindaban con el río Carcarañá que, como se observa en el plano, se hizo extensivo al resto de los dueños.

Las tierras públicas fueron subdivididas, como ya se dijo, en suertes de estancias (en naranja) y, como es posible observar, correspondían al sector noroeste del departamento y se extendían hacia el norte provincial donde la calidad de las mismas iba disminuyendo. De estas ventas el gobierno nacional obtuvo $\$ \mathrm{f}^{5} 204500$ y con ese monto se hizo frente a las expropiaciones.

El ingeniero De Laberge incluyó los nombres de los empresarios rurales que compraron dichos terrenos en el sector de interés de este artículo, con un total de 19 unidades (en verde) los inversores fueron: Zubelzu compró las suertes 35, 39 y 43; Arzac, la número 36; Aldao, las 37 y 38; Parfait, la 40; Devoto, la 41; Simpson, la 44; Brandt, las 45 y 52; la Compañía Talbot, Richardson, Trail \& Cape las suertes 42, 46, 50 y 53; Ledesma, las 47 y 48; Bolleart, la 49; y, Thomas Thomas, la 51.

Estas 19 suertes de estancia con una extensión total de 69 leguas cuadradas ingresaron al mercado de tierras que, como se verá en los siguientes apartados, en lo que resta del siglo xix y principio del xx fueron cambiando de dueños, parcelándose, subiendo de precios, convirtiéndose en colonias y pueblos. Con el correr del tiempo se transformaron terrenos de pastos y montes sin población residente en campos productivos arrendados y explotados por familias de colonos en su mayoría inmigrantes, es decir, el monte se fue talando, las tierras, que parecían infinitas, se delimitaron con alambrado y las construcciones de ladrillos fueron emergiendo en el ambiente y convirtiéndose en un paisaje ruralizado.

\section{El espacio fronterizo: caracterización sociogeográfica de tierras revalorizadas}

El paisaje cultural es resultado de la acción del desarrollo de actividades humanas en un territorio concreto, cuyos componentes identificativos son: el sustrato natural (orografía, suelo, vegetación, agua) y la acción humana, entendida por la modificación o alteración de los elementos naturales y construcciones para una finalidad concreta y la actividad desarrollada (componente funcional en relación con la economía, formas de vida, creencias, cultura, etcétera) (Centro del Patrimonio Mundial, 2008).

En este caso se presenta el proceso de construcción de un paisaje cultural pampeano ocurrido en la segunda mitad del siglo xIx, cuya base natural fueron extensas tierras

\footnotetext{
${ }^{5} \$$ f: pesos fuertes.
} 
uniformes con leves ondulaciones, cubiertas por montes achaparrados, pajonales y amplias superficies libres de vegetación. A esta monotonía solo la quebraba un curso de agua salada denominado cañada San Antonio, límite natural con la provincia de Córdoba que atraviesa la región de norte a sur, y que fue el único sitio de referencia fijo en el territorio durante el siglo xIx (Figura 3, A y B).

Figura 3. Fotografías contemporáneas del límite natural interprovincial. A. En periodo de sequía (2009) se observa el salitrado de los suelos. B. Periodo de régimen de lluvias regular (2021); en esta también es posible observar el mojón que indica el límite entre ambas provincias datado en 1884 (fotografías de la autora)
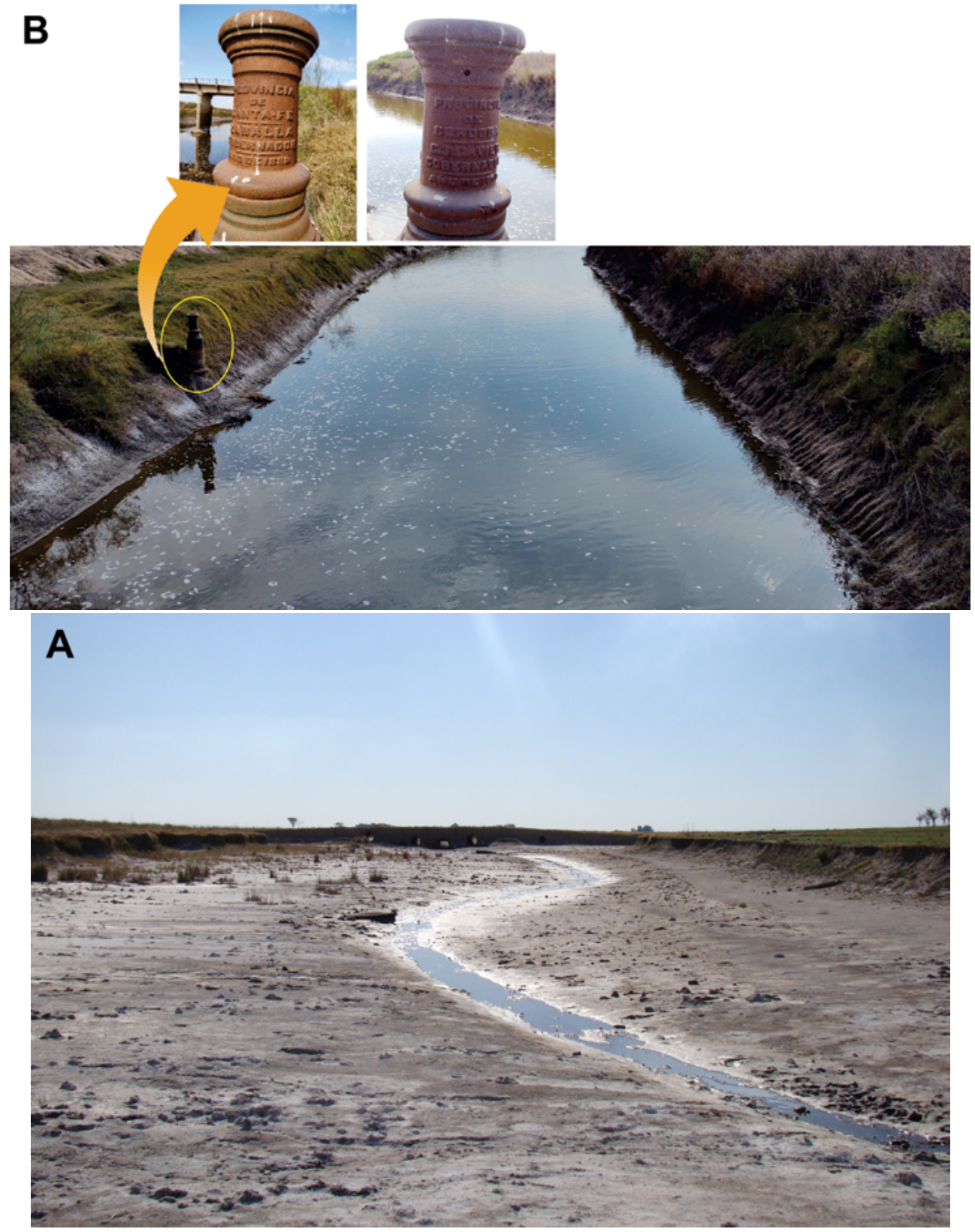
Se trata de una depresión lineal somera y relativamente ancha, de traza recta y bordes definidos, que funciona como colector local del escurrimiento superficial de los bañados. Desemboca al sur parcialmente hacia el río Carcarañá a través del arroyo Las Tortugas. Su escasa pendiente y la alta rugosidad provocada por la presencia de vegetación hacen que el escurrimiento sea muy lento y concentra temporariamente las aguas (Carignano et al., 2014; Fresina, 2001; Manavella \& Iriondo, 1984). Este estancamiento ha provocado que los suelos se hayan enriquecido de sales y que la calidad de las tierras lindantes no sea originariamente buena para la agricultura; sin embargo, a mayor distancia de la cañada los suelos con color ligeramente rojizo y con un porcentaje de materia orgánica y arcilla sí eran fértiles (Scobie, 1964). De clima templado, con las cuatro estaciones del año bien demarcadas y un régimen de lluvias que oscila entre los $700 \mathrm{~mm}$ a $1000 \mathrm{~mm}$, les permitió a las poblaciones radicadas desde la segunda mitad del siglo xIx a la actualidad desarrollar actividades agropecuarias con éxito (Gallo, 2004).

El salitrado de las aguas de la cañada San Antonio fue el principal impedimento para que poblaciones indígenas se asentaran y que fuese desde tiempos prehistóricos solo una zona de tránsito entre el río Carcarañá y las sierras centrales cordobesas (Ceruti, 1998).

Desde el periodo colonial y hasta el siglo xIx ese paisaje inhóspito, frontera interprovincial con densa vegetación, sirvió de refugio para los que huían de la justicia, que con el tiempo se convertían en individuos fronterizos o gauchos matreros. El impacto devastador de las guerras civiles, invasiones o saqueos sucedidos a lo largo de los primeros 20 años del siglo xix otorgaron un carácter peculiar a la sociedad provincial que vivía en estado de alerta permanente (Gallo, 2004). En tiempos inmediatos a la colonización, para atravesar las pampas era necesario estar armado debido a la alta presencia de bandidos rurales y en estos campos se erigían ranchos pertenecientes a estos gauchos matreros portadores de una vida marginal que rastrillaban la región robando ganado y bienes transportados por los arrieros, tanto en beneficio propio como de quienes los contrataban para eso (Caldcleugh, 1825; Ortiz Gambetta, 2013; Gentile, 2013). El término bandidos rurales hace referencia a las bandas de salteadores que tenían como principal escenario de actuación las rutas que unían a Buenos Aires con Santa Fe y Córdoba (Fradkin \& Ratto, 2009) y está cargado de significados ${ }^{6}$ al tratarse de una reacción espontánea e individual de los sectores menos favorecidos frente a la violencia impuesta por el Estado, por lo que fueron respetados por los desposeídos y combatidos por la Ley ya que buscaron transgredir al desafiar simultáneamente al orden económico, social y político (Hobsbawm, 1999).

Hacia la década de 1840, las guerras civiles disminuyeron y la provincia comenzó a reorganizarse geográfica y socialmente. La relativa pacificación permitió la reactivación del tráfico interprovincial y nuevas estancias fueron formándose en las inmediaciones de los principales centros urbanos (Gallo, 2004); aunque fue hasta entrada la segunda mitad del siglo xIx que la provincia comenzó a progresar a ritmo sostenido.

En el periodo que abarca de 1858 a 1869 se produjeron grandes avances sobre el territorio indígena, lo que permitió asegurar la región norte de la ciudad de Santa Fe de las incursiones de estos grupos originarios. Hacia 1864 se consolidó el extremo este de la frontera norte al reforzar el límite del pueblo de San Javier y, de igual manera,

${ }^{6}$ Por ejemplo, es rescatado por la cultura popular a través de expresiones artísticas como música (León Gieco, Bandidos Rurales, álbum de estudio del año 2001) y literatura (David Viñas, 2011). 
en 1869, se avanzó en línea recta hacia el oeste y se consolidó la línea de fortines desde San Javier hasta Soledad y Morteros (Carrasco, 1888), la frontera sur se aseguró muy por debajo del río Carcarañá a la altura del departamento General López (Figura 4). Esta consolidación fronteriza le permitió incorporar tierras vírgenes al dominio provincial y, como se vio en el apartado anterior, colocarlas en el mercado aseguradas de invasiones indígenas (Ministerio de Gobierno, 1866, p. 453).

Figura 4. Con base en el plano diseñado por Carrasco (1886), en el área de estudio se delimitan en violeta los avances del control territorial a través del establecimiento de nuevas líneas de fortines. Se hace hincapié en el límite interprovincial, su consolidación coincide con la del proceso colonizador de la región

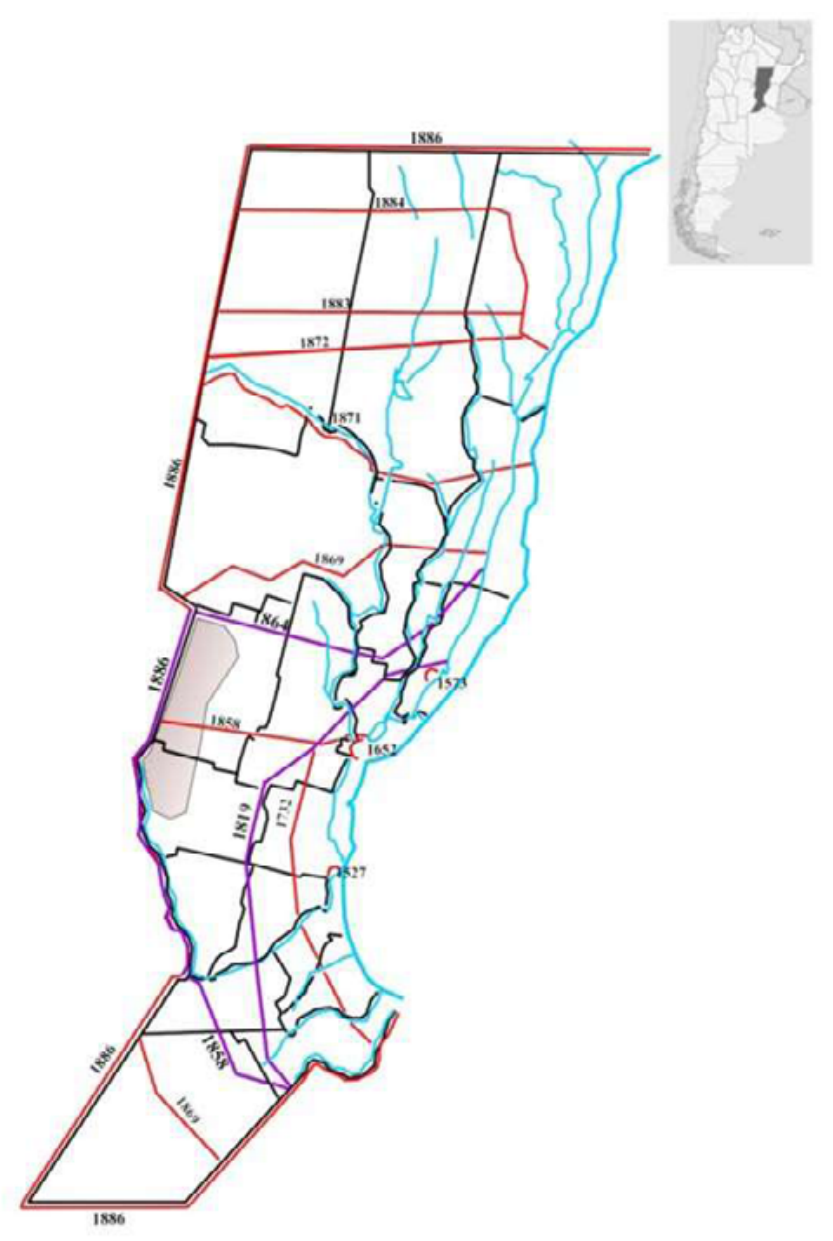

La transformación de estas tierras llamadas desierto ${ }^{7}$ comenzó, como se planteó en líneas anteriores, con su venta a empresarios rurales y comerciantes, en su mayoría radicados en la ciudad de Rosario, en combinación con la seguridad social y jurídica brindada por el Estado provincial.

${ }^{7}$ Se entiende como desierto al área por fuera del ámbito del control efectivo del Estado y de la influencia de las primeras colonias agrícolas portadoras de civilización. 
Fue así como estos múltiples factores incidieron favorablemente en la economía rural de la provincia y permitió el poblamiento de tierras que hasta unos años atrás eran consideradas inhóspitas. Como se verá a continuación, el área estudiada ingresa al mercado en 1866 pero es hasta la década de 1880 cuando comienzan a formarse las primeras colonias agrícolas.

\section{El departamento San Gerónimo: su evolución territorial}

El departamento San Gerónimo es uno de los cuatro en que estaba divida la provincia de Santa Fe a inicios del siglo xix; junto a los departamentos San José, La Capital y Rosario fue fundado con fines políticos y administrativos en 1826 con capital en el distrito Coronda. Con una superficie original de 14712 km², sufrió subdivisiones en distintas décadas decimonónicas, por lo que en particular los campos estudiados fueron cambiando de dominio departamental. Al norte limitaba con el departamento La Capital y los tres restantes límites eran cursos de agua: el río Paraná al este, la cañada San Antonio al oeste y al sur el río Carcarañá.

En 1883, por el aumento de la población provincial, la misma se subdividió en nueve departamentos. Producto de esto, con el sector sur de su territorio se conformó el departamento Iriondo. En este periodo su superficie pasó a ser de $9000 \mathrm{~km}^{2} \mathrm{y}$ su territorio estaba comprendido entre el río Paraná, al norte el departamento Las Colonias, al sur una línea paralela al límite norte que se extendía desde la confluencia del río Carcarañá y Paraná, pasaba por las propiedades de los señores Alzogaray, Lafone, Chavarri, Smith y Smithies, Tregasthen, Fraire, Espinosa, Thomas y al oeste el límite interprovincial con Córdoba (Carrasco, 1886). En 1890 se realizó su última subdivisión ${ }^{8}$ y su sector oeste se convirtió en el departamento San Martín; por lo que su superficie se redujo a $4282 \mathrm{~km}^{2}$ y el nuevo departamento pasó a ser su límite oeste (Figura 5). A partir de esa fecha, el área de particular interés pasó a formar parte del nuevo departamento San Martín, por lo que se analizará solo su evolución parcelaria.

En relación con la evolución de la tenencia de la tierra del departamento San Gerónimo, posteriormente San Martín, se parte de la primera fuente catastral localizada (De Laberge, 1867) para luego ir introduciendo sucesivos planos catastrales (Carrasco, 1889; Chapeaurouge, 1872, 1901; Ludwing, 1895) que dan cuenta de la expansión territorial producto de la implantación de una política pobladora que fomentaba la colonización capitalista por intermedio de empresas, lo que llevó a la intensificación del trabajo agrícola y a la parcelación de la tierra. El marco temporal elegido se apoya en la cuestión central de ser el periodo en que el proceso colonizador vivió su auge y consolidación.

\footnotetext{
${ }^{8}$ Si bien no afecta al área de interés, se considera de relevancia indicar que en 1907 la provincia tuvo su última modificación administrativa territorial al crearse el departamento 9 de Julio, al norte, con tierras del departamento Vera y San Cristóbal y en ese mismo año Reconquista cambió su denominación a General Obligado.
} 
Figura 5. Divisiones departamentales de la provincia de Santa Fe. En cada mapa se indica la ubicación del departamento San Gerónimo y pueden observarse los departamentos que se desprenden de él. Elaboración propia con base en Carrasco, 1886; Ludwing, 1895; y, Martirén, 2015
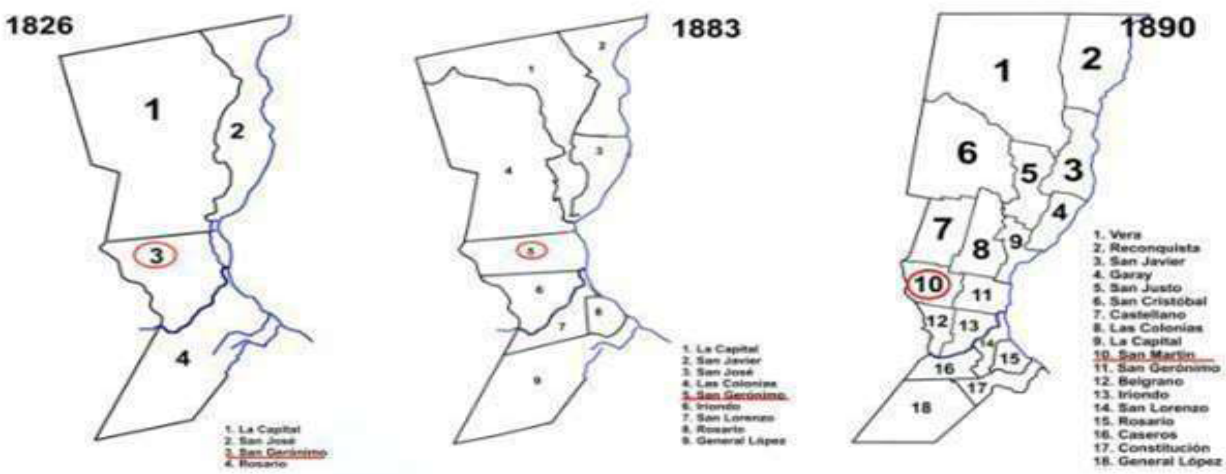

\section{Paisaje cultural pampeano: las colonias como nueva unidad territorial} y su desarrollo en el área de estudio

De acuerdo con lo desarrollado hasta el momento, en el periodo inmediato a la ejecución de la primera obra ferroviaria interprovincial, el departamento San Gerónimo presentaba estancamiento económico, despoblamiento e inseguridad por la amenaza indígena.

Esta situación no era exclusiva, sino que eran factores generalizados de la provincia, por lo que los sucesivos gobiernos de la segunda mitad del siglo xxi apostaron a abandonar los circuitos marginales de producción con un programa de modernización que implicaba el ingreso de capital y fuerza de trabajo extranjero.

Para ello fue necesario quebrar con el sistema de producción ganadero herencia del periodo colonial; fue así, como se verá a lo largo de este apartado, que en esta etapa la colonia se convirtió en la nueva unidad territorial y la chacra en la unidad productiva.

Fueron tres las variables que convergieron para que este cambio fuera posible: parcelación, poblamiento y expansión productiva. Y son ellas las que se tendrán en cuenta para analizar cada uno de los planos catastrales que dan cuenta de este proceso de cambio y de ingreso al sistema capitalista de producción.

El primero de ellos es el plano que el ingeniero Albano M. de Laberge, que como se vio en líneas anteriores, hizo para la Compañía del Ferrocarril Argentino en 1867. En el plano de elaboración propia, con base en el original, se puede observar la convivencia del pasado y del futuro plasmados gráficamente y separados por una frontera difusa remarcada en color anaranjado (Figura 6).

El pasado estaba materializado en las grandes estancias vacunas de límites borrosos, emblema del poder terrateniente, que para prosperar necesitaban de causes de agua naturales debido al bajo nivel de inversión por los propietarios. 
Mientras que el futuro, se materializaba en un programa de soberanía territorial que era urgente ejecutar y en el que las exigencias de la compañía ferroviaria y de la pobreza de las arcas provinciales incidieron en su aceleración. La expropiación de campos y la expansión territorial hacia el sector sin títulos de propiedad potenció un mercado de tierras que llamó la atención de empresarios rurales que en búsqueda de inversiones diversificadas introdujeron nuevas prácticas productivas y nuevas tecnologías (Zeberio, 2007) para así otorgarle valor agregado a tierras que por siglos permanecieron inertes y que les permitiera hacer frente a los desafíos venideros.

De Laberge identificó a 43 previos propietarios del lindero al trazado ferroviario, así como hacia el centro este del departamento; a ellos se suman los dueños del área de nuevas subdivisiones colindante a la frontera provincial: tierras fiscales devenidas en suertes de estancia.

Figura 6. Plano de elaboración propia con base en el original del ingeniero De Laberge (1867) que tiene como objetivo la representación gráfica del primer avance sólido de consolidación de un nuevo sistema de propiedad y explotación territorial en el área de estudio

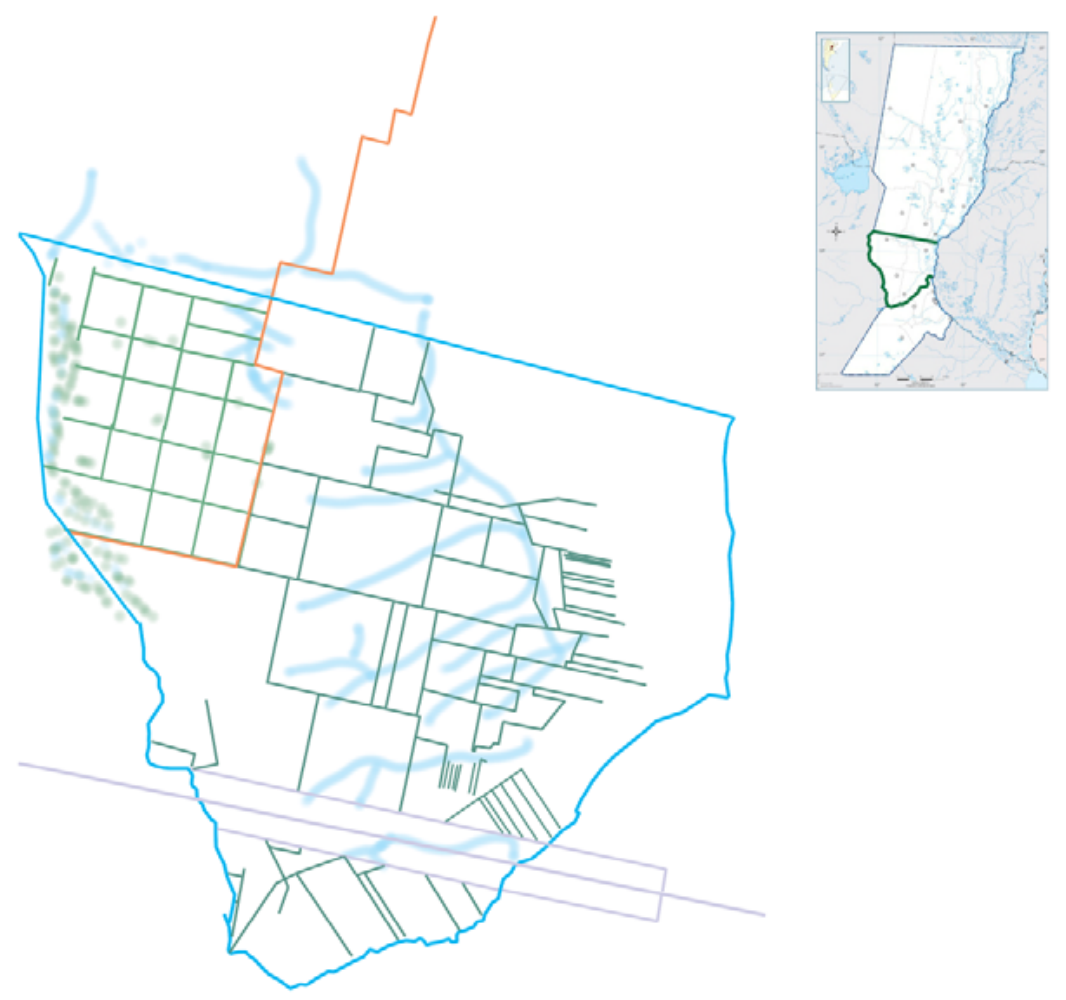

Como se expresó en los apartados anteriores, el proceso de parcelación fue progresivo y llevó aproximadamente 40 años; es así como todavía hacia fines de 1860 la concentración de capitales estuvo lejos de caer y por el contrario San Gerónimo ostentó los valores más altos de concentración de la riqueza provincial (Frid, 2010). 
Este paulatino fraccionamiento se observa 15 años después, en el segundo plano catastral considerado en este estudio: el de Carlos de Chapeaurouge (1872).

Este es el primer plano topográfico completo de la provincia de Santa Fe y una deuda que fue necesaria saldar para poseer una real forma, aprehensible, visible y, sobre todo, mostrable (Dócola et al., 2008). Mostrable con el objetivo de atraer inversionistas e inmigrantes que comenzaran a explotar esas vastas tierras que por primera vez materializaban sus reales límites (Figura 7).

Figura 7. Representación gráfica en la cual se superponen ${ }^{9}$ los planos originales del ingeniero De Laberge (1867) y del agrimensor Carlos Chapeaurouge (1872). A simple vista los cambios no son significativos, pero marcan el inicio de un proceso que se sostendría en el tiempo

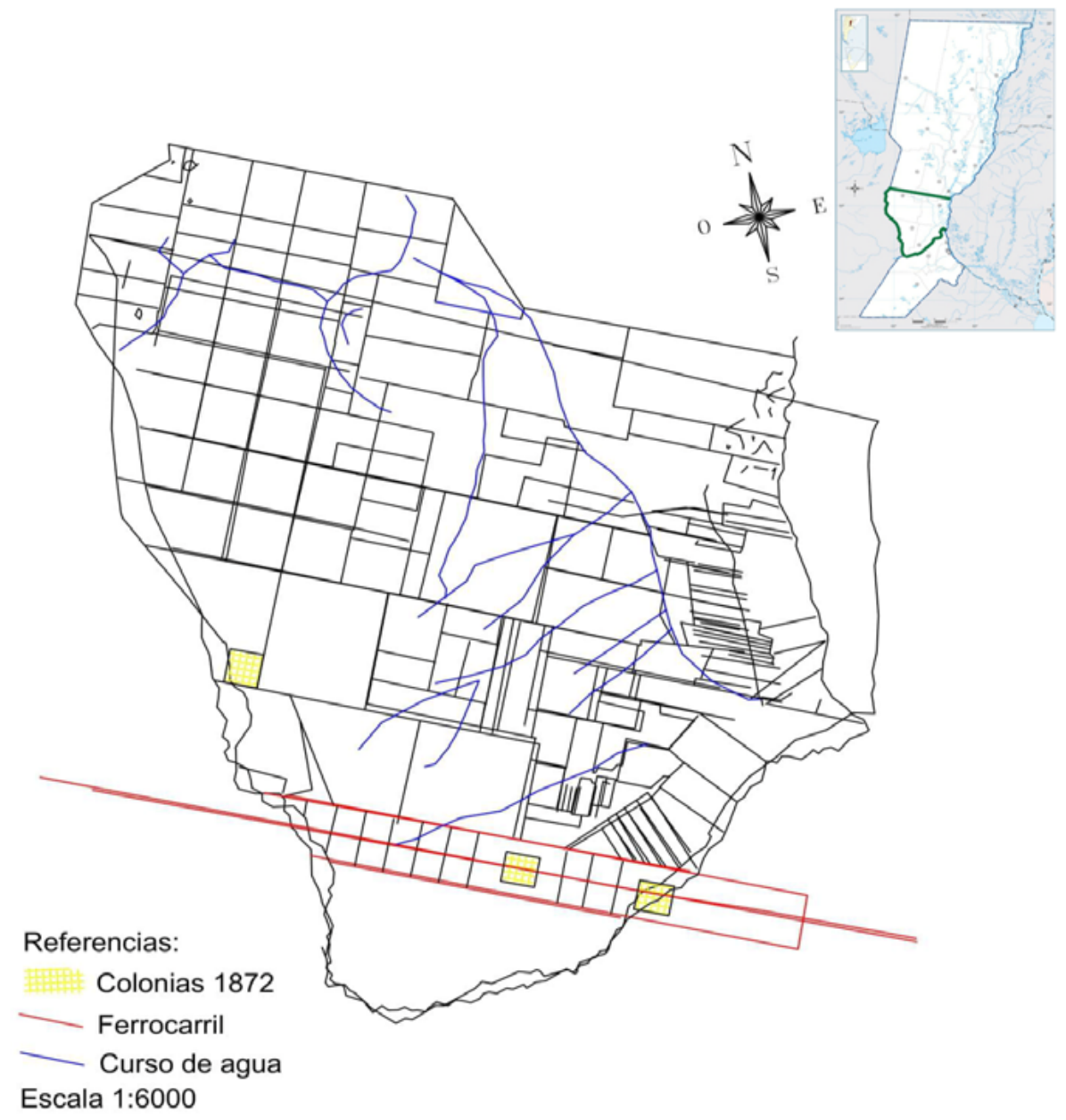

${ }^{9}$ Esta representación gráfica, como las subsiguientes, fueron posible gracias a la colaboración de la agrimensora Marina Cardonato (Núm. de matrícula: 2-0482-0, Colegio de Profesionales de la Agrimensura de la Provincia de Santa Fe, Argentina). 
Como puede observarse en la Figura 7, la subdivisión se dio específicamente en dos sectores, ambos en áreas adyacentes a las nuevas suertes de estancia. Uno en el sector inmediato inferior y el otro a su oeste. Fue posible identificar 151 propiedades, solo $18 \%$ más que en el periodo anterior, en manos de 128 propietarios, es decir, que la concentración de la tenencia de las tierras todavía preponderaba en el departamento.

Son tan solo tres colonias fundadas (Carcarañá, Cañada de Gómez y Jewell). Estas aparecen representadas con un cuadriculado que da cuenta del nuevo sistema de división de la tierra que se buscaba imponer. Las dos primeras pertenecen a la Compañía de Tierras del Central Argentino; en Carcarañá se encontraban radicadas 102 familias, 89 de ellas se dedicaban a la agricultora y en total en esta colonia habitaban 510 personas. Mientras en Cañada de Gómez, una población de 335 habitantes conformaba 67 familias, de las cuales 46 eran colonas (Wilcken, 1873). Por su parte, si bien colonia Jewell tuvo existencia legal por aprobación de la traza (Montenegro, 1994), por parte del Departamento de Topografía provincial nunca tuvo una existencia real ya que no radicaron familias.

A partir de los albores de 1870 , las colonias se fueron fundando a un ritmo sostenido transformándose en la unidad territorial por excelencia, dando lugar a las chacras de chica y mediana superficie como el sistema productivo predilecto que sustituyó progresivamente a las extensas estancias (Bonaud et. al., 1992; Bonaudo \& Sonzogni, 2000).

Figura 8. Representación gráfica en la cual se superponen los planos originales del agrimensor Carlos Chapeaurouge (1872) y de Gabriel Carrasco (1889), director del primer censo poblacional de la provincia. Las áreas cuadriculadas muestran el avance de la fundación de colonias, así como la subdivisión de las grandes estancias

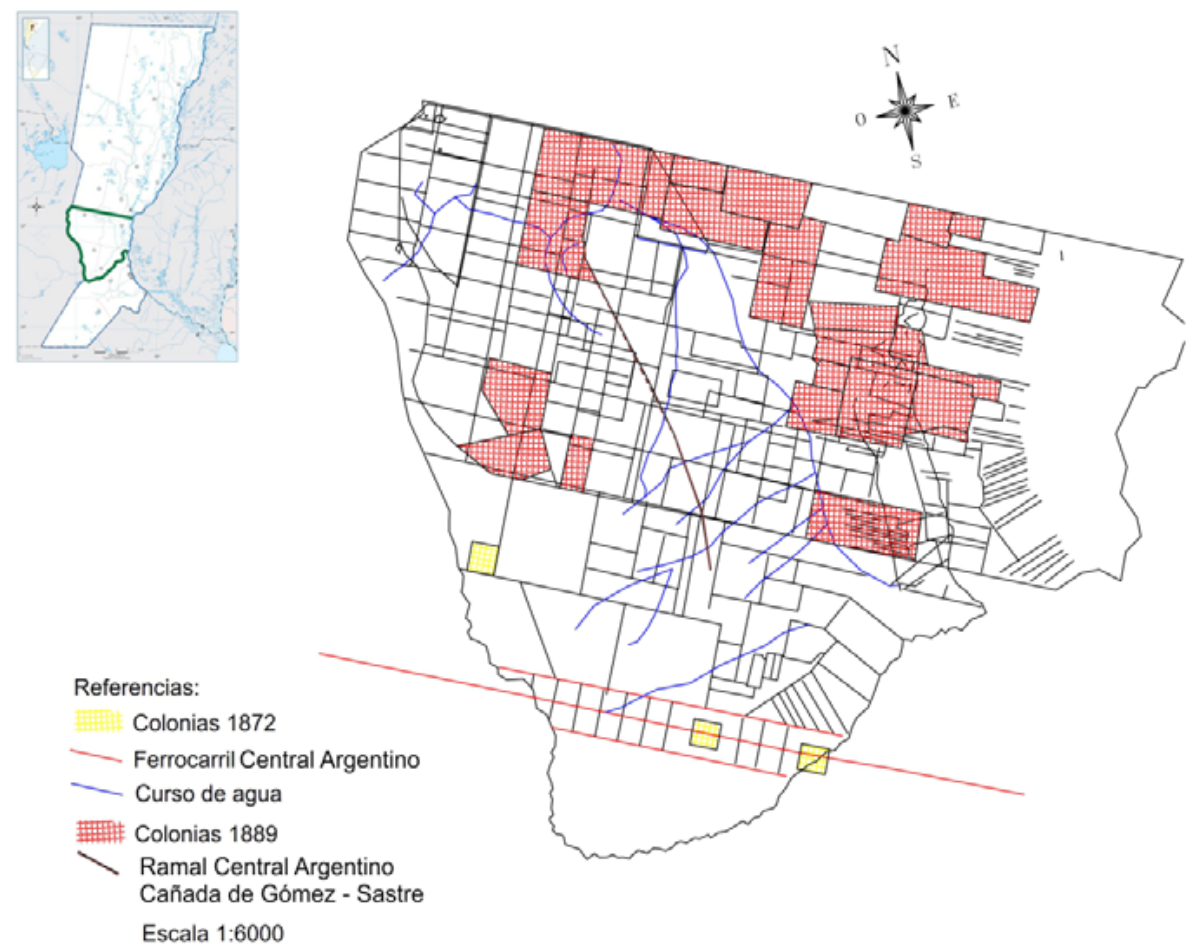


Hacia finales de la década de 1870 la población iba en ascenso demográfico, así como la demanda por tierras para trabajar y la campaña santafesina empezó a mostrar cambios significativos con respecto al paisaje relevado por Chapeaurouge en 1872. Como lo muestra el plano catastral de la Figura 8 (Carrasco, 1889), las colonias fueron ocupando las extensas zonas dedicadas a la ganadería, y las estancias supervivientes pasaron a un segundo plano. A su vez, sufrieron cambios a nivel productivo al combinar la ganadería con agricultura (Gallo, 2004), lo que modificó su dinámica al recibir periódicamente a "trabajadores golondrina" ${ }^{10}$ para levantar las cosechas. Por lo que la región se pobló con migración extranjera y de las provincias limítrofes.

Este plano da cuenta de la primera subdivisión que sufrió el departamento San Gerónimo, en la que conservó el sector norte. El proceso de colonización había comenzado y parecía no tener fin, por lo que resultó ser necesario darle un marco legal y en octubre de 1884 se promulgó la primera ley de tierras. ${ }^{11}$ En los artículos 80 al 90 especifica los requisitos necesarios para que particulares funden colonias agrícolas.

Esta ley representa el primer antecedente de planificación de la urbanización del área rural santafesina. Las colonias debían estar atravesadas por calles cada cuatro concesiones con un ancho de 20 metros y de 15 metros en los pueblos. La principal motivación para convencer a los terratenientes de ingresar al sistema de colonización fue la excepción de pagos de impuestos por seis años para aquellas colonias de más de una legua cuadrada de superficie y que se encontraran a más de 20 leguas de distancia de un ferrocarril o río navegable y por tres años a aquellas distantes a 15 leguas.

Este sistema es conocido como colonización privada (Gallo, 2004). En el cual el empresario rural compraba a precio de mercado una porción de tierra de una o más leguas cuadradas, las subdividía y vendía al mejor postor o parcelaba y vendía propiedades que había comprado décadas atrás para conformar así colonias agrícolas con una población espontánea.

Además del marco legal, la administración provincial necesitaba contar con un relevamiento demográfico de su población. Por lo que en 1887 organizó y ejecutó el primer censo poblacional de la provincia. Según el cual el departamento San Gerónimo poseía 20997 habitantes; 5687 habitaban las áreas urbanas y 15310 la campaña.

Al tomar de referencia el plano topográfico de 1889 y cotejarlo con lo relevado durante dicho censo, se puede observar que su división se ha complejizado a nivel de urbanización y administrativo. El primero porque las antiguas colonias comenzaron a formar sus propias áreas urbanas producto del paso de la primera línea férrea que partía desde Cañada de Gómez y terminaba en Colonia Sastre atravesando numerosas propiedades que pronto iban a ingresar al mercado de la colonización, y el segundo porque el Estado provincial definió distritos con cabecera en las ciudades más desarrolladas para que se encargaran de la administración pública de las colonias de sus alrededores. La Tabla 1 da cuenta de la organización del departamento a fines de la década de 1880 .

\footnotetext{
${ }^{10}$ Se considera como "trabajadores golondrina" a los trabajadores rurales migrantes estacionales (Andreani, 2013), y en su origen hace alusión a los inmigrantes atraídos por la primavera local para la cosecha, a la vez que huían de la escasez laboral de la estación invernal europea y retornaban del viejo continente en la temporada de verano.

${ }^{11}$ Ley de Tierras de la Provincia de Santa Fe, 28 de octubre de 1884. El Senado y Cámara de Diputados (Carrasco, 1886).
} 
Tabla 1. División política-administrativa del departamento San Gerónimo (Carrasco, 1888)

\begin{tabular}{|c|c|c|}
\hline Departamento San Gerónimo & Habitantes & Total \\
\hline Coronda (ciudad) & 2255 & \\
\hline Colastine & 465 & \\
\hline \multirow[t]{2}{*}{ Lomas } & 453 & \\
\hline & & 3273 \\
\hline \multicolumn{3}{|l|}{ Oroño y Gessler } \\
\hline Oroño (pueblo) & 171 & \\
\hline Oroño (resto de la colonia) & 251 & \\
\hline Gessler (pueblo) & 341 & \\
\hline Gessler (resto de la colonia) & 587 & \\
\hline Resto del distrito & 1000 & 2350 \\
\hline Gálvez (pueblo) & 646 & \\
\hline Colonia Margarita & 132 & \\
\hline Campo Aldao & 132 & \\
\hline Campo de Giménez & 129 & \\
\hline Monte de José Ñudo & 222 & \\
\hline Campo de Irigoyen y otros & 110 & \\
\hline Monte Ralo & 274 & 1645 \\
\hline Belgrano (pueblo) & 77 & \\
\hline Resto del distrito & 1327 & 1404 \\
\hline San Martín de las Escobas (pueblo) & 440 & \\
\hline Resto del distrito & 1570 & 2010 \\
\hline $\begin{array}{l}\text { Sastre: Ortíz, Concepción y San Jorge } \\
\text { (colonias) }\end{array}$ & 292 & \\
\hline Cañada San Antonio & 458 & 750 \\
\hline Piamonte (colonia) & 410 & \\
\hline Nueva Creación (resto del distrito) & 404 & 814 \\
\hline San Genaro (pueblo) & 285 & \\
\hline Resto de la colonia & 925 & \\
\hline San Agustín (campo colonizado) & 258 & \\
\hline Bustinza (campo colonizado) & 118 & \\
\hline
\end{tabular}




\begin{tabular}{|c|c|c|}
\hline Monte del Gato & 129 & \\
\hline Carrizales Afuera & 472 & 2187 \\
\hline Irigoyen (pueblo) & 417 & \\
\hline Irigoyen (resto de la colonia) & 2474 & \\
\hline Campo de Aldao & 57 & \\
\hline Colastiné & 292 & 3240 \\
\hline Gaboto (pueblo) & 732 & \\
\hline Gaboto (resto) & 405 & \\
\hline Díaz (pueblo) & 224 & \\
\hline Puerto Aragón & 99 & \\
\hline Puerto Aragón (fluvial) & 7 & \\
\hline \multirow[t]{2}{*}{ Barracas (resto del distrito) } & 1857 & 3324 \\
\hline & & 20997 \\
\hline
\end{tabular}

Como se ve, a 20 años del inicio del proceso, la parcelación del departamento y de toda la provincia adquirió una complejidad que incluía: colonias, distritos, establecimientos de campo, parajes con denominación propia y pueblos con una tasa mayor de población en las áreas rurales; a nivel productivo confluían tres métodos: la estancia agrícola-ganadera, la chacra (mano de obra familiar) y la fuerza de trabajo estacional (trabajadores golondrina asalariados).

Hacia mediados de la década de 1890, los particulares continuaron subdividiendo sus grandes estancias y las entregaban a familias de colonos para el cultivo en medianas y pequeñas parcelas o bien arrendaban toda la propiedad. Este sistema de manejo de la tierra y la multiplicación de vías férreas que surcaban a lo largo y ancho la provincia significó la decisión definitiva de entregar el proceso colonizador a manos privadas y con ella la transformación agrícola del perfil de la provincia (Cárcano, 1972).

Desde 1895, la tierra pública ya no existe y todo el suelo está apropiado por el trabajo y el capital (Bonaudo \& Sonzogni, 2000), lo que hace que las tierras suban su valor y el acceso a la propiedad raíz se vea limitada por lo que aparecen nuevas formas de contrato: peonazgo, arrendamiento y mediería.

En este periodo el departamento sufrió su última subdivisión y como el interés principal de este artículo es la consolidación de la frontera oeste, a partir de ahora se enfocará en el devenir del nuevo departamento: San Martín. El plano catastral relevado por Pablo Ludwing con fecha de 1895 da cuenta de esta separación (Figura 9).

El sector norte del departamento fue tributario de las corrientes colonizadoras provenientes de los departamentos Las Colonias y Castellanos que poseían escasas tierras libres de colonización (Gallo, 2004); mientras que el sector sur fue recibiendo los remanentes de inmigrantes que no encontraron su lugar en los departamentos más australes. 
Figura 9. Representación gráfica en la cual se superponen los planos originales de Carrasco (1889) con el plano original de Ludwing (1895) donde se resalta en naranja la subdivisión departamental y es posible observar la consolidación de la frontera oeste gracias a una alta tasa de parcelación y presencia de explotaciones agrarias

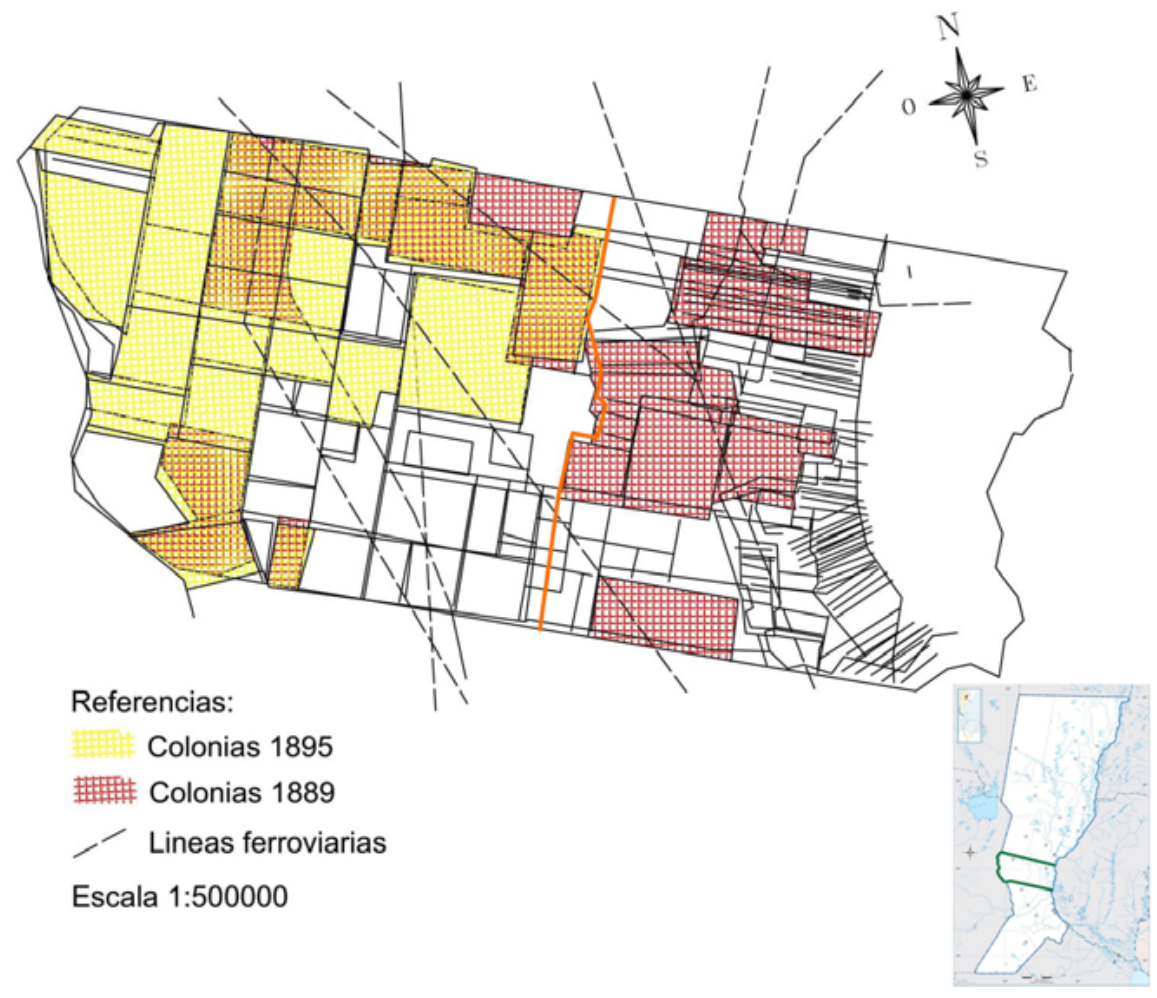

Es interesante remarcar que el sector sureste permanecía hacia fines del siglo xix sin ingresar al mercado de tierras y sus dueños conservaban sus grandes propiedades con una explotación mixta, como se vio en líneas atrás, que combinaba ganadería y agricultura.

En el mismo año de la publicación de este plano se realizó el segundo censo de la República Argentina y al comparar ambos registros se puede establecer cómo el departamento San Martín se encontraba organizado y el total de sus habitantes (Tabla 2) (De la Fuente, 1898).

Entonces, el departamento estaba dividido en cuatro distritos que administraban colonias con población urbana y rural salvo dos casos de un pueblo (Tais) y una colonia con solo población rural (Las Yerbas). La zona rural contaba con mayor población, $87 \%$ del total habitaban en la campaña.

En 1901 se publicó la primera edición del Atlas del Plano Catastral de la República Argentina a cargo del reconocido Carlos de Chapeaurouge y, a diferencia del resto, se trató de una iniciativa privada por lo que no tuvo un destino fiscal (Favelukes, 2015). En tanto sí lo tuvo la actualización del contexto, expansión, ocupación y distribución de tierras, de la construcción de los ferrocarriles y del trazado definitivo de las fronteras, ya que se habían producido importantes cambios desde 1895 . 
Tabla 2. Población urbana y rural de las divisiones geográficas y administrativas del departamento San Martín

\begin{tabular}{|c|c|c|c|c|}
\hline Distrito & Nombre del pueblo o colonia & Urbana & Rural & Total \\
\hline Belgrano & Belgrano & 224 & 687 & 861 \\
\hline \multirow[t]{9}{*}{ Piamonte } & Carlos Pellegrini & & 2322 & \\
\hline & Castelar & & 362 & \\
\hline & Crispi & 80 & 342 & \\
\hline & Las Petacas & & 319 & \\
\hline & Piamonte & & 460 & \\
\hline & San Martín de Las Escobas & & 548 & \\
\hline & Tais & 333 & & \\
\hline & Thomas y Cárcano & & 237 & \\
\hline & El Trébol & & 3303 & 8306 \\
\hline \multirow[t]{3}{*}{ San Martín } & Armstrong & 150 & 1354 & \\
\hline & Castro & & 148 & \\
\hline & San Martín & 570 & 4540 & 6762 \\
\hline \multirow[t]{3}{*}{ Sastre } & Sastre y Ortiz & 615 & 1271 & \\
\hline & Las Yerbas & & 300 & \\
\hline & San Jorge & 619 & 1443 & 4248 \\
\hline Total & & 2591 & 17636 & 20177 \\
\hline
\end{tabular}

El cambio más significativo fue hacerle frente a las nuevas exigencias (Bonaudo \& Sonzogni, 2000). Es decir, ocupar el territorio ya no era una prioridad sino trabajarlo de un modo que se obtuviera el mejor provecho: intensificar y diversificar la explotación rural.

En el cambio de siglo fue un nuevo requerimiento aumentar y abaratar la producción para equilibrar la situación financiera del país. Lo que llevó, en 1898, a realizar una investigación, ordenada por el Congreso Nacional, de la situación agrícola que reunió un inmenso material de observaciones de criterio científico (Cárcano, 1972). La última fuente catastral Chapeaurouge (1901), puede considerarse un resultado de esos estudios agrarios. Estos arrojan resultados positivos para la provincia de Santa $\mathrm{Fe}$ cuya campaña presentaba un escenario orgánico y equilibrado.

En relación con este escenario, el plano (Figura 10) da cuenta de que a nivel local $70 \%$ de la superficie del departamento San Martín se encontraba cultivada (Cárcano, 1972) y coexistían propietarios, agricultores, estancieros, arrendatarios y medieros. Esta explotación intensiva de las tierras encontró apoyo en nuevas líneas férreas que llevaban la producción a los graneros de la ciudad de Rosario. 
Figura 10. Representación gráfica en la cual se superponen los planos originales de Ludwing (1895) con el plano original de Chapeaurouge (1901). Se observa cómo en los albores del siglo $\mathbf{X X}$, con un programa agrario afianzado, las chacras agrícolas siguen coexistiendo con algunas de las antiguas estancias de producción mixta
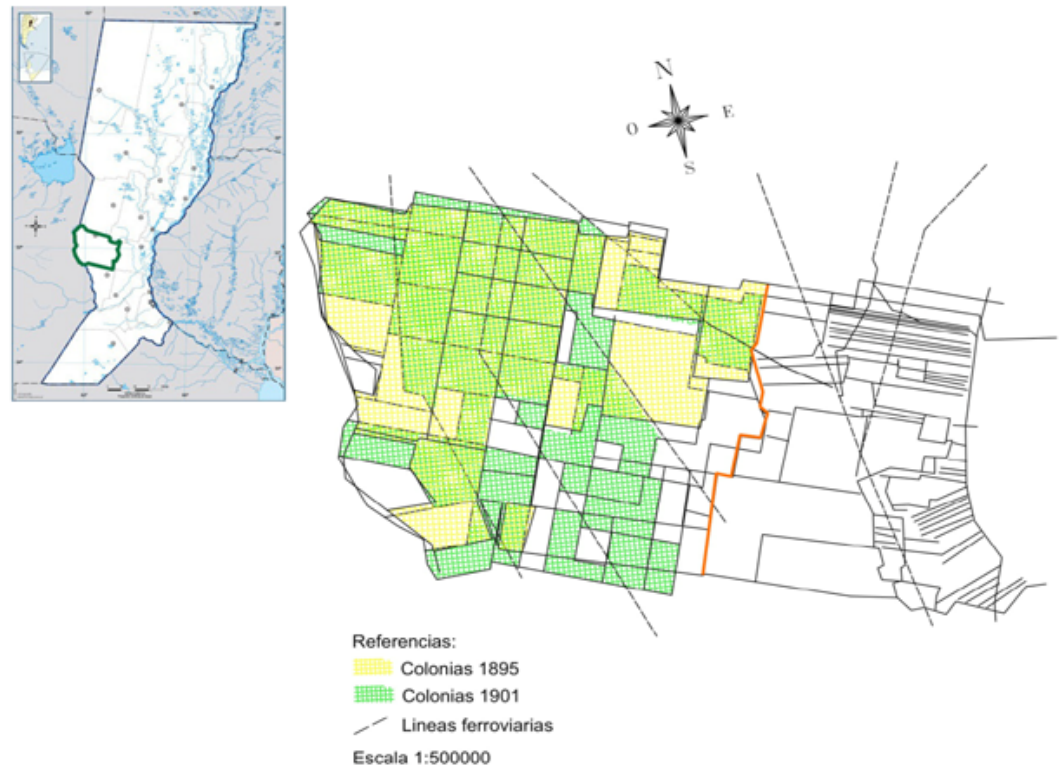

La Tabla 3 da cuenta de los datos consignados por el agrimensor y fue posible identificar tres clases de unidades territoriales.

De un total de 51 unidades territoriales, $53 \%$ corresponde a colonias agrícolas, $41 \%$ a estancias y $3 \%$ a paradas de las distintas líneas de ferrocarril. Para poder interpretar la matriz productiva del departamento se tomó como fuente complementaria el segundo censo agropecuario realizado en 1908 (República Argentina, 1909). Según el registro censal, el departamento San Martin tenía una extensión de 446400 ha y en esa área estaban en explotación 2909 unidades productivas que variaban en extensión y en actividad.

De ese total de hectáreas 212362 estaban destinadas a una producción mixta, 53600 solo a agricultura y 180438 a ganadería; lo que pone en discusión el imaginario social que sostiene que en su mayoría las colonias eran agrícolas. La preponderancia de la ganadería responde a la realidad agroecológica de los suelos. Los mismos en su mayor proporción eran francos y algo fuertes, aptos para la agricultura pero que hacia el oeste se volvían más livianos con pastos naturalmente tiernos, aprovechables para la cría de ganado y cultivo de alfalfa (Lavenir, 1909). 
Tabla 3. Unidades territoriales existentes en el departamento San Martín de acuerdo con el catastro del plano de Carlos de Chapeaurouge (1901)

\begin{tabular}{|c|c|c|c|}
\hline $\mathbf{N}^{\circ}$ & Colonias & Estaciones de ferrocarril & Estancias de \\
\hline 1 & Castelar & Oroño & Jewell Hnos. \\
\hline 2 & Las Petacas & Trail & C. Arteaga \\
\hline 3 & Santa Anita & Casas & Fa. de Yrigoyen \\
\hline 4 & Normando & & Didd Norton y Jackson \\
\hline 5 & Piamonte & & Diego Simpson \\
\hline 6 & Colonia Thomas & & Espinosa \\
\hline 7 & Crispi & & D. Munro \\
\hline 8 & Las Yerbas & & Wildermuth \\
\hline 9 & Landeta & & C. L. Duarte \\
\hline 10 & Ortiz & & Las Castañas Hnos. Dickinson \\
\hline 11 & San Jorge & & J. Cane \\
\hline 12 & El Ingerto & & J. Bertel \\
\hline 13 & Del Bajo & & La Nata \\
\hline 14 & Sastre & & Benedetto \\
\hline 15 & Concepción & & Basualdo \\
\hline 16 & Las Limpias & & Nuñez \\
\hline 17 & Carlos Pellegrini & & Faleu \\
\hline 18 & La Caledoña & & Basualdo \\
\hline 19 & Las Taperas & & A. Juárez \\
\hline 20 & Los Laureles & & La Francia \\
\hline 21 & Cárcano & & Juan Watt \\
\hline 22 & San Martín & & \\
\hline 23 & San Genaro & & \\
\hline 24 & Armstrong & & \\
\hline 25 & Cañada Rosquín & & \\
\hline 26 & Santo Tomás & & \\
\hline 27 & Belgrano & & \\
\hline
\end{tabular}

Como se observa en este último plano y constatado con la información brindada en el censo es posible confirmar que, a 50 años del inicio del proceso de control territorial a través de la parcelación y colonización, los tiempos de desolación, aislamiento y estancamiento económico habían quedado atrás. Es así como la tierra fue productivamente ocupada, si bien se mantenían estancias de 2500 ha y más, la mayor cantidad de parcelas en producción eran de tamaño mediano sin superar las 300 ha (Figura 11). En ellas se sembraba mayoritariamente trigo, seguido por maíz y en menor proporción cebada, avena, lino y alfalfa para corte. Mientras el maíz y 
la alfalfa se sembraban en primavera y requerían de mano de obra en otoño para su cosecha, la recolección del resto de los cultivos era en primavera.

Figura 11. Con los datos arrojados por el Censo Agropecuario de 1908 se demuestra que las proporciones de medianas fracciones de campo superaban con creces a las grandes estancias supervivientes

\section{Número de propiedades}

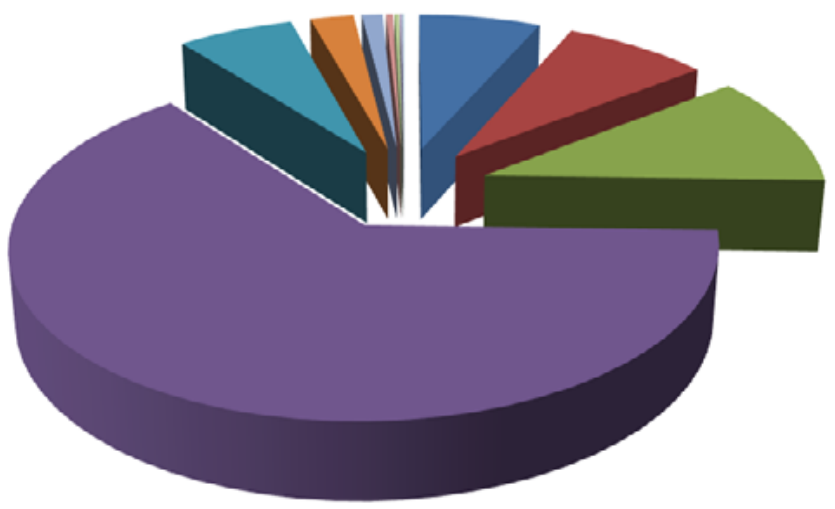

10 y menos

घ 11 a 50

51 a 100

101 a 300

301 a 500

501 a 1000

1001 a 2500

2501 a 3750

Entonces, la concentración de trabajadores golondrina se daba entre la primavera y el otoño del año siguiente y estos estaban formados por inmigrantes internacionales temporales, peones rurales originarios de las provincias del norte del país, trabajadores urbanos y productores rurales de pequeñas parcelas; todos ellos buscaban generar un ingreso significativo que implicaba un gran aporte a la economía familiar.

El avance de la parcelación no significó acceso a la propiedad sino a unidades productivas en arriendo o aparcería explotadas por grupos familiares. En este contexto hubo familias colonas que perdieron sus concesiones ${ }^{12}$ mientras que otras ampliaron las suyas. Estos últimos recurrieron a la presencia de otros inmigrantes sin tierras bajo la figura de habilitado o del mediero ${ }^{13}$ (Barsky \& Gelman, 2009). Es así como, a través de 40 años, el entramado social que desarrolló la producción agropecuaria se fue complejizando de acuerdo con el acceso a la tierra y el capital de los productores. De un escenario compuesto de arrieros ganaderos se pasó a uno de familias colonas de propietarios, arrendatarios, medieros y trabajadores asalariados. Esta reestructuración que revolucionó ese paisaje fronterizo y aislado es posible reconocerla inclusive un siglo después.

\footnotetext{
${ }^{12}$ Las causas de las pérdidas son disímiles: cultivos en zonas no adecuadas, sequías, plagas de langostas, altos costos de insumos y servicios agropecuarios, etcétera.

${ }^{13}$ Por habilitado o mediero se entiende a inmigrantes sin recursos a los que se les proveía de todos los elementos para la explotación agropecuaria y por cuyo trabajo cobraban una parte de la cosecha (Djenderedjian, 2012).
} 


\section{Conclusiones}

Progresivamente, y a lo largo de 40 años, el paisaje del centro oeste santafesino y de la provincia de Santa Fe pierden su chata y árida fisonomía producto del desarrollo colonizador que a través de la subdivisión de la tierra en pequeñas y medianas propiedades ha ido introduciendo núcleos artificiales de producción agrícola: las colonias.

A través del estudio de la cartografía histórica se pudo observar que la primera forma de subdivisión de las tierras fronterizas fue la suerte de estancias, lo que dio batalla al desafío de expansión productiva por medio de la incorporación de inmigrantes europeos y así proporcionarles un cierre a siglos de estancamiento económico heredado del periodo colonial.

Si bien este proceso fue más lento y con resultados heterogéneos que dependían del tamaño de la propiedad a la que la familia colona pudo acceder, del régimen de tierras, de la calidad de los suelos, de la inestabilidad climática, de la invasión de langostas, de la distancia a las líneas férreas, el modelo agropecuario pampeano tendió con el paso de los años a homogeneizarse. Sentó las bases del modelo imperante a nivel nacional: el agroexportador.

Su implementación fue un método de prueba y error que no siempre dio resultados positivos ni para los gobiernos, ni para los empresarios rurales, ni para los inmigrantes que en más de una oportunidad no lograron acceder a la posesión definitiva de las tierras trabajadas.

Como se vio a lo largo del artículo, este proceso de evolución vertiginosa implicó no solo cambios a nivel productivo (parcelación de tierras, agriculturización y modernización tecnológica) sino también a nivel social (inmigrantes, arrendatarios, propietarios, peones rurales permanentes y transitorios).

Si bien las políticas apostaron a una agricultura extensiva (preponderantemente trigo, maíz y lino) en el departamento San Gerónimo y luego en su sección que conformó el departamento San Martín, esta convivió hasta entrado el siglo xx con las estancias ganaderas donde predominó una explotación agropecuaria mixta que permitió la supervivencia de los productores frente a los avatares político-económicos, la variabilidad edáfica y climática.

La cartografía histórica da cuenta del proceso de parcelación de las tierras, formación de colonias y centros urbanos, pero también de la conservación de las estancias en manos de grandes terratenientes. Es así como el trabajo familiar en las medianas y pequeñas chacras coexistían con los peones asalariados de las grandes extensiones productivas.

De esa manera, el paisaje sufrió una profunda modificación dejando a un lado la desolación, aislamiento e improductividad colonial. La desolación se combatió con una sostenida política inmigratoria, el aislamiento con la conexión ferroviaria y la improductividad con la habilitación al acceso a la tierra por vastas capas de productores.

Esta variabilidad de productores a principios de siglo xx se aunó con la categoría de chacareros y en ella se incluían a propietarios, arrendatarios y medieros. Estos chacareros eran los que predominaban, según el registro censal de 1908, en el departamento San Martín, con unidades de explotación que no superaban las 300 ha.

Al describir las transformaciones tanto geográficas y sociales de estas tierras marginales y fronterizas se puede aseverar que el proceso fue particularmente notable. Ya que a pesar de un aporte estatal inconstante se pudo en un par de décadas 
consolidar un modelo productivo agroexportador que coloca a la provincia de Santa

Fe como uno de los principales productores de la materia prima requerida.

\section{Referencias}

Andreani, H. (2013). Migración, maíz y silencio. Aproximaciones al bilingüismo (quichua-español) de los trabajadores 'golondrina' de Santiago del Estero (Argentina). Gazeta de Antropología, 29(1). http://dx.doi.org/10.30827/Digibug. 24585

Barsky, O. \& Gelman, J. (2009). Historia del agro argentino, desde la Conquista hasta fines del siglo Xx. Sudamericana.

Bonaudo, M., Cragnolino, S. \& Sonzogni, E. (1992). Poblamiento y desarrollo económico: tres experiencias de los ochenta. Revista de Historia, (3), 3-26. http://revele. uncoma.edu.ar/htdoc/revele/index.php/historia/article/view/811

Bonaudo, M. \& Sonzogni, E. (2000). Cuando disciplinar fue ocupar (Santa Fe, 185090). Mundo agrario, 1(1). https://www.mundoagrario.unlp.edu.ar/article/ view/MAv01n01a03/1559

Caldcleugh, A. (1825). Travels in South America, during the years 1819-20-21 (vol. II). Murray.

Cárcano, M. A. (1972). Evolución histórica del régimen de la tierra pública 1810-1916. Editorial Universitaria de Buenos Aires.

Carignano, C., Kröhling, D., Degiovanni, S. \& Cioccale, M. (2014). Geomorfología. En R. Martino \& A. Guereschi (Eds.), Relatorio del XIX Congreso Geológico Argentino Geología y Recursos Naturales de la Provincia de Córdoba (pp. 747-822). Asociación Geológica Argentina. https://www.researchgate.net/publication/278242641_ Geomorfologia_de_la_provincia_de_Cordoba_Argentina

Carrasco, G. (1886). Descripción geográfica y estadística de la Provincia de Santa Fe. Stiller \& Laass. https://archive.org/details/descripcingeog00carr/page/n5/mode/2up

Carrasco, G. (1888). Primer Censo General de la Provincia de Santa Fé (libro vi). Jacobo Peuser.

Carrasco, G. (1889). Plano de la Provincia de Santa-Fé. Departamento de Documentos Escritos (Mapoteca II-224), Archivo General de la Nación, Buenos Aires, Argentina.

Centro del Patrimonio Mundial. (2008). Directrices Prácticas para la aplicación de la Convención del Patrimonio Mundial. Unesco.

Ceruti, C. (1998). La tradición de las llanuras centrales. En C. Ceruti (Coord.), Arqueología del nordeste argentino (pp. 181-197). Facultad de Filosofía y Letras-Universidad de Buenos Aires.

Chapeaurouge, C. de (1872). Mapa de la Provincia de Santa -Fé. (s.l.: s.n), Museo Mitre N¹91, Ciudad Autónoma de Buenos Aires, Argentina.

Chapeaurouge, C. de (1901). Atlas del plano catastral de la República Argentina (Hoja N³9). Eigendorf y Lesser. https://www.loc.gov/resource/g5350m.gct00165/?sp=44

Djenderedjian, J. (2012). Gringos en las pampas: inmigrantes y colonos en el campo argentino. Sudamericana. 
De la Fuente, D. G. (1898). Segundo Censo de la República Argentina, mayo 10 de 1895 (vol. 2). Taller Tipográfico de la Penitenciaria Nacional.

De Laberge, A. M. (1867). Trayecto del ferrocarril central argentino del Rosario de Santa Fé a la ciudad de Córdoba: plano de los terrenos concedidos a la empresa por Ley Nacional el 26 de Mayo de 1863. (s.n.t.: 1), Museo Mitre N540. Ciudad Autónoma de Buenos Aires, Argentina.

Dócola, S. A., Geremía, C., Payró, P. \& Puig, M. (2008). Una bota en el desierto Santa Fe, 1887. Registros. Revista de Investigación Histórica, (5), 75-86. https://revistasfaud.mdp.edu.ar/registros/article/view/363

Dosztal, I. (2017). Alexandra Colony: arqueología histórica en su sede administrativa. Colonización británica en Santa Fe, Argentina. Publicia.

Dosztal, I. (2018). Tomas Thomas: empresario rural inserto en un proceso de transformación territorial (Colonia Carcarañá, Santa Fe, Argentina 1871-1908). Cadernos do Lepaarq, 15(30), 38-55. https://doi.org/10.15210/lepaarq.v15i30.13131

Favelukes, G. N. (2015). El país en un libro: parcelas, mensuras y territorio en catastros tempranos en la Argentina. REDES, 21(40), 177-195. http://www.unq.edu.ar/ advf/documentos/58b0712d2c0de.pdf

Ferns, H. S. (1968). Gran Bretaña y Argentina en el siglo XIX. Solar/Hachette.

Fradkin, R. \& Ratto, S. (2009). Desertores, bandidos e indios en la frontera de Buenos Aires, 1815-1819. Secuencia, (75), 11-41. https://doi.org/10.18234/secuencia. v0i75.1087

Fresina, M. E. (2001). Comportamiento hidrogeológico-hidroquímico del acuífero pampeano en la cuenca inferior del río Carcarañá, provincia de Santa Fe (Tesis doctoral, Universidad de Buenos Aires).

Frid, C. (2010, 23 de noviembre). Desigualdad y crecimiento económico: un análisis de la distribución espacial y social de la riqueza en Santa Fe (185-1870). [Documento de conferencia]. Decimoquintas Jornadas "Investigaciones en la Facultad" de Ciencias Económicas y Estadística. Universidad Nacional de Rosario. Repositorio Hipermedial UNR. https://rephip.unr.edu.ar/bitstream/handle/2133/8246/ Frid $\% 2 \mathrm{C} \% 20$ desigualdad $\% 20 y \% 20$ crecimiento $\% 20$ economico $\% 20$.pdf?sequence $=3 \&$ isAllowed $=\mathrm{y}$

Gallo, E. (2004). La pampa gringa. Edhasa.

Gentile, M. E. (2013). Trasfondo medieval de los relatos acerca de gauchos matreros pero milagreros (República Argentina, siglos xIX-XxI). Revista Folklore, (381), 29-46. https://www.folkloretradiciones.com.ar/folklorecientifico/documentos/trasfondo\%20medieval\%20gauchos\%20matreros.pdf

Hobsbawm, E. (1999). Bandidos. Crítica.

Lanteri, A. L. (2013). Acerca del aprendizaje y la conformación político-institucional nacional: Una relectura de la "Confederación" argentina (1852-1862). Secuencia, (87), 69-94. http://www.scielo.org.mx/scielo.php?script=sci_arttext\&pid=S0186-03482013000300004\&lng=es\&tlng=es

Lavenir, P. (1909). Agrología de la República Argentina. En República Argentina, Censo Agropecuario Nacional, la Ganadería y la Agricultura en 1908 (t. III, pp. 153-184). Talleres de Publicaciones de la Oficina Meteorológica Argentina. 
Ludwing, P. (1895). Plano topográfico catastral de la Provincia de Santa-Fé. Registro grafico de las propiedades rural. Mapoteca Sala Manuel Selva (BNA_MA003908), Biblioteca Nacional Mariano Moreno de la República Argentina, Ciudad Autónoma de Buenos Aires, Argentina. https://catalogo.bn.gov.ar/F/?func=find-c\&ccl_ter$\mathrm{m}=\% 28+\mathrm{WRD}+\% 3 \mathrm{D}+\%$ 28+BNA_MA003908+\% 29+\% 29+and+\% 28+WSL+\%3D $+\%$ 28+MAPO+\%29+\%29\&local_base=GENER

Manavella, C. \& Iriondo, M. (1984). Rasgos geológicos e hidrogeológicos de la cuenca del Arroyo San Antonio. Provincia de Santa Fe [artículos de libros]. Publicado en: 9o. Congreso Geológico Argentino. Bariloche. Actas, v. 6.

Martirén, J. L. (2015). El fin del yermo. La emergencia de un nuevo mercado inmobiliario rural y los precios de la tierra en las colonias agrícolas de la provincia de Santa Fe, Argentina (1860-1895). Mundo Agrario, 16(32), 1-32. https://www. mundoagrario.unlp.edu.ar/article/view/MAv16n32a01

Mejía, H. R. S. (2012). Composición, mercedes de tierras realengas y expansión ganadera en una zona de frontera de la gobernación de Santa Marta: Valledupar (1700-1810). Anuario colombiano de historia social y de la cultura, 39(1), 81-117.

Miguez, E. (1985). Las tierras de los ingleses en la Argentina (1870-1914). Editorial de Belgrano.

Ministerio de Gobierno. (1866). Diligencia de mensura de los terrenos medidos para la comisión encargada de la expropiación de tierras para el Ferro Carril Central Argentino (Tomo 29, Exp. 016, Folio 414). Archivo General de la Provincia de Santa Fe. Santa Fe, Argentina.

Montenegro, L. (1994). Evolución de la propiedad rural en la antigua jurisdicción de San Jerónimo, en la segunda mitad del S. xix. En I Jornadas de Historia del Desarrollo Urbano y Rural en la antigua jurisdicción de San Jerónimo. (t. I, pp. 28-45). Subsecretaría de Cultura de la Provincia de Santa Fe.

Ortiz Gambetta, E. (2013). De "matrero" a símbolo nacional: la imagen literaria del gaucho en dos novelas argentinas del siglo XIx. Anales de Literatura Hispanoamericana, 42, 199-213. https://doi.org/10.5209/rev_ALHI.2013.v42.43663

Reguera, A. (1999). Estancias pampeanas del siglo xIx. Estrategia empresaria para su funcionamiento: chacras agrícolas y puestos ganaderos. Quinto Sol, (3), 53-82. https://doi.org/10.19137/qs.v3i0.640

República Argentina. (1909). Censo Agropecuario Nacional, la Ganadería y la Agricultura en 1908 (3 vols.). Talleres de Publicaciones de la Oficina Meteorológica Argentina.

Scalabrini Ortíz, R. (1958). Historia de los Ferrocarriles Argentinos. Plus Ultra.

Scobie, J. R. (1964). Revolution on the Pampas: a social History of Argentine wheat, 18601910. University of Texas Press.

Viñas, D. (2011). Policiales por encargo (Colección Los raros). Biblioteca Nacional.

Wilcken, G. (1873). Las Colonias. Informe sobre el estado actual de las colonias agrícolas de la República Argentina. Sociedad Anónima.

Zeberio, B. (2007). Un mundo rural en cambio. En M. Bonaudo (Dir.), Nueva historia argentina. Liberalismo, Estado y orden burgués (1852-1880) (pp. 293-362). Sudamericana. 
Irene Dosztal

Argentina. Doctora en antropología de la Facultad de Humanidades y Artes de la Universidad Nacional de Rosario. Actualmente es docente-investigadora de la Universidad Nacional de Rosario, Unidad de Investigación en Historia Regional (ISHIR-UNR). Líneas de investigación: problemáticas asociadas a la colonización de la Provincia de Santa Fe durante la segunda mitad del siglo xix desde un abordaje histórico arqueológico. Publicación reciente: Dosztal, I. \& Valentini, M. (2021). Thomas y su rol en Graneros y Muelles del Rosario. Consolidación de una red social en un contexto de capitalismo periférico. Rosario-Santa Fe (1879-1892). Anuario de Arqueología, (13). https://doi.org/10.35305/aa.v13i13.72 